\title{
RESPONSES OF MALE TROPICAL MOCKINGBIRDS TO VARIATION IN WITHIN-SONG AND BETWEEN-SONG VERSATILITY
}

\author{
Carlos A. Botero and Sandra L. Vehrencamp \\ Lab of Ornithology and Department of Neurobiology and Behavior, Cornell University, Ithaca, NY \\ 14850
}

\begin{abstract}
Despite their large vocal repertoires and otherwise highly versatile singing style, male mockingbirds sometimes sing in a highly repetitive fashion. We conducted a playback experiment to determine the possible signal value of different syllable presentation patterns during simulated male intrusions in the Tropical Mockingbird (Mimus gilvus) testing the hypothesis that more repetitive singing represents a stronger threat and generates a stronger aggressive response. Responses were measured in terms of approach and singing behavior and were analyzed using McGregor's (1992) multivariate method. We also introduce the use of survival analysis for analyzing response variables for which subjects do not perform the behavior in question in at least one of the replicates (known as 'rightcensored variables' in the statistical literature). As predicted by theory, experimental subjects responded more aggressively to songs composed of a single note than to variable ones. However, versatility at the between-song level had an opposite effect as high song switching rates generated stronger responses than low ones. Given the lack of a statistical interaction between within-song versatility and switching rate, we conclude that these two parameters may serve independent purposes and possibly transmit different information. We discuss the possibility that the signal value of variation in vocal versatility lies in the mediation of territorial conflicts, the attraction of female partners and/or the mediation of conflicts over access to reproductive females.
\end{abstract}

\section{Keywords}

mockingbird; survival analysis; song complexity; switching rate; versatility

\begin{abstract}
Many oscine songbirds with discrete song repertoires vary their song type switching rate in different social contexts (Lemon 1968; Dixon 1969; Lein 1978; Falls and D'Agingcourt 1982; D'Agingcourt and Falls 1983; Ritchison 1988; Searcy and Yasukawa 1990; Horn and Falls 1991; Wiley et al. 1994; Langmore 1997; Molles and Vehrencamp 1999). Some playback studies have shown that male songbirds not only respond to variation in the switching rate of their rivals (Kramer et al. 1985; Nielsen and Vehrencamp 1995; Searcy et al. 1995) but also vary their own switching rate as they become more aggressive (Falls and Krebs 1975; Searcy et al. 2000). As a general rule, males in species that normally sing with high switching rates tend to become more repetitive in increasingly agonistic situations whereas those that normally repeat each song type several times before singing a different one tend to do the opposite (reviewed in Vehrencamp 2000). Because of these divergent coding patterns, switching rate is thought to be a conventional signal of aggressive intentions (Vehrencamp 2000).
\end{abstract}

Corresponding author: Carlos A. Botero, Bioacoustics Research Program, Cornell Lab of Ornithology, 159 Sapsucker Woods Rd., Ithaca, NY 14850, Email: cab82@cornell.edu. 
Mimus mockingbirds are renowned for their large vocal repertoires and highly versatile singing style (Brewer and MacKay 2001). Their songs are made of a finite number of short (ca. 0.31s), acoustically distinct sounds known in the Northern Mockingbird (M. polyglottos) as song types (Derrickson 1987) or syllable types (Wildenthal 1965). We refer to these units as syllables because this term is consistent with the terminology used in most other studies on songbirds (see Read and Weary 1992; Catchpole and Slater 1995).

Song versatility, continuity of singing, and repetitiveness of sequential syllables have been shown to vary contextually in the Northern Mockingbird (Burnett 1978; Derrickson 1988; Derrickson and Breitwisch 1992). In the spring, males typically sing each syllable type several times in a bout before switching to a different one, show long recurrence intervals before singing the same syllable type, and make brief or no substantial pauses between consecutive bouts (i.e., are continuous singers). Fall song, on the other hand, is significantly less repetitive and contains a larger proportion of temporally discrete multiple-syllable phrases lacking any repetition (Burnett 1978). Aggressive response is stronger to playback of spring song than of fall song during both seasons (Logan and Fulk 1984). During the breeding season, syllable versatility is highest and bout length is shortest for unmated and courting males, compared to those singing during the incubation and nestling stages (Derrickson 1988). In the context of territorial patrolling and countersinging with a rival male, singing is even more repetitive and less versatile, brought about by an increase in bout length, a decrease in recurrence intervals, and a reduction in presentation of rare syllable types (Derrickson 1988). Although these studies find a consistent pattern of greater syllable repetition and lower versatility associated with more aggressive contexts, a systematic investigation of the independent effects of repetitiveness (e.g. bout length) and vocal versatility on behavioral responses has not been undertaken. Moreover, such a study would be difficult to achieve in the Northern Mockingbird because the two singing patterns are confounded.

The Tropical Mockingbird is closely related to the Northern Mockingbird and strongly resembles it in both appearance and behavior (the two species can hybridize in sympatry, Howell and Webb 1995). Although males in both species sing syllables with similar general structure, consistency of delivery, and duration (Fig. 1), Tropical Mockingbirds throughout most of their range are not continuous singers but rather sing temporally discrete "songs" like those of most other songbirds. The songs of the Tropical Mockingbird are typically composed of less than ten syllables and sometimes include three or more different syllable types (i.e., a singing style that resembles the structure of the Northern Mockingbird's fall song). Although males at our study site are primarily immediate variety singers (Fig. 1a), individuals conspicuously vary their vocal versatility (Fig. 1b) and may alter the repetitiveness of their syllable sequences during countersinging.

We conducted a playback experiment to determine the possible signal value of different syllable presentation patterns during simulated male intrusions in the Tropical Mockingbird. Based on the patterns observed in the Northern Mockingbird (Derrickson 1988) and the fact that the typical, non-aggressive singing style of Tropical Mockingbirds at our study site is highly versatile (Fig. 1a), we test the hypothesis that more repetitive singing represents a stronger threat and generates a stronger aggressive approach. Because of their discontinuous singing style, Tropical Mockingbirds can become more repetitive by singing songs composed of a single syllable type, by repeating the same song several times, or both. We make no a priori hypothesis about the specific mechanism through which repetitiveness is achieved but rather test for the effects of within-song versatility (i.e., song complexity) and between-song versatility (i.e., switching rate) on male response through an experiment with a factorial design. In our playback sequences we controlled for other potential acoustic signals in male-male interactions such as repertoire size, duty cycle (i.e., the fraction of the total playback time in 
which the recorded bird actually sings), song length, song quality, song rate, and song amplitude.

\section{Methods}

\section{Study population}

Our experiment took place at the private ranch Kunuku Warahama, on the island of Bonaire, Netherlands Antilles (12 $07^{\prime} 11^{\prime \prime}$ N, $68^{\circ} 15^{\prime} 07^{\prime}$ 'W) from late May to early August of 2003 . The natural habitat of Bonaire is a very dry forest (sensu Holdridge 1967) with a yearly annual precipitation of under $560 \mathrm{~mm}$, a mean daily temperature of $30^{\circ} \mathrm{C}$, and a single rainy season from October to January. At Kunuku Warahama, single breeding pairs of tropical mockingbirds defend multipurpose territories from other conspecifics and evict their young within one or two months after fledging $(n=5)$. Territories are maintained year-round and are roughly circular in shape (ca. $200 \mathrm{~m}$ in diameter). Individuals without a territory are usually forced into areas with low habitat quality but often attempt to take over already occupied territories by force. Although we have no quantitative data on the frequency or distribution of these territorial intrusions, our observations suggest that they can occur at any time during the year and that intruders can be both males and females. Tropical mockingbirds in Bonaire may breed year round in territories near permanent water sources such as public wells or human habitation. However, due to the high seasonality of the island, breeding is most often observed close to or during the rainy season.

\section{Experimental design}

Prior to this experiment, we color-banded 13 paired males and established their territorial boundaries. Gender was determined through behavioral observations collected during 2002 and 2003. Clues to sexual identity included role during copulation, nesting behavior (males build most of the outer cup of the nest and females tend to help with the lining), incubating behavior (only female mockingbirds incubate), singing behavior (males sing disproportionately more than females) and territorial responses towards other individuals of known sex (each sex tends to be more aggressive towards its own kind). We subjected each male to four different types of conspecific playback (i.e., four different playback treatments) in a factorial design with high or low song complexity and high or low between-song switching rate, plus a heterospecific control treatment (Fig. 2). Each subject heard songs from the same non-neighboring individual in all trials (different subjects heard different birds). Although several of our focal males had bred from May to August in 2002, none of them initiated reproduction during this study due to the dry conditions experienced in 2003 (two focal males temporarily increased their song output but did not reach the normal output observed during courtship/mate stimulation). We exposed each subject to only one trial per day and tested him again three or more days later while balancing the order of presentation of treatments across birds. Although we performed at least two trials per treatment and one control on every bird, our statistical analyses do not include data from 11 trials that were discarded due to problems with our recording equipment and 13 more that were discarded because we lost track of the focal bird before the end of the post-playback observation period or because more than one male responded to the playback. Our final sample size comprised 85 successful trials with conspecific song sequences and 10 with heterospecific controls; 11 of the 13 focal males were successfully subjected to at least one trial for every treatment.

\section{Generation of playback stimuli}

We created seven different "playback sets" (i.e., the four combinations of high/low song complexity with high/low switching rate) using song recordings collected from seven colorbanded males at the same study population in 2002 . These recordings were made at $48 \mathrm{kHz}$ and 16 bits per sample using a Marantz portable PC card recorder PMD690 and a Sennheiser 
ME67 directional microphone. Due to the extensive behavioral observations we had previously done on this population, males were accustomed to human presence and typically allowed us to record them from a distance of $10-25 \mathrm{~m}$. All sound manipulations we describe below were done digitally using the sound analysis software SYRINX, version 2.1 (see Acknowledgements).

We generated each playback set by first creating high and low between-song switching rate treatments with complex songs extracted from high quality recordings (i.e., recorded at close range, good signal to noise ratio, no overlapping sounds and little to no detectable reverberation). We then obtained the corresponding two other treatments by replacing each complex song with a digitally derived repetitive song (see below). High switching rate treatments consisted of a one-minute sequence of seven different songs by a single male repeated four times (i.e., 1, 2, 3, 4, 5, 6, 7, 1, 2, etc...). Low between-song switching rate treatments consisted of the same 28 songs and inter-song intervals but each song type was presented four times before introducing the next one (i.e., 1, 1, 1, 1, 2, 2, 2, 2, 3, etc...). To create repetitive songs we took a single syllable from the complex songs and repeated it several times until achieving similar song duration (Fig. 2; mean duration of songs $=2.06 \mathrm{~s} ; \mathrm{SD}=0.71 \mathrm{~s}$; $\min =0.88 \mathrm{~s} ; \max 3.73 \mathrm{~s}$ ). In this process we deliberately used syllables that would produce repetitive songs that resembled those we had previously heard in the wild (note the duration of our repetitive songs is well within the range of natural repetitive songs, e.g. Fig. 1b). We chose to generate repetitive songs out of complex ones (as opposed to using recorded repetitive songs from the same male) because this procedure allowed us to produce playback sets with equivalent recording quality, song quality, duty cycle, song rate and song duration. To test whether generating repetitive songs out of a single syllable had any influence over the outcome of our experiment, we also generated heterospecific controls by repeating single syllables of sympatric troupials (Icterus icterus, Figs. 2e and 2f). In natural situations troupials sing repetitive sequences of a single syllable type that do not evoke aggressive responses in mockingbirds.

\section{Playback procedures and response measures}

We placed a single speaker (RadioShack amplified speaker system AMX 18) in a bush at a known border of the territory of the test subject and played back the song sequences using a laptop computer and a $50 \mathrm{~m}$ connection cable. Playback intensity was standardized to $70 \mathrm{~dB}$ SPL measured at $3 \mathrm{~m}$. We used flagging tape to mark concentric rings that defined distance bins at distances of 15, 25 and $50 \mathrm{~m}$ from the speaker. Trials were executed between 0630 and 1000 hours and started after the test subject had been spotted within $100 \mathrm{~m}$ from the speaker.

Each trial consisted of five min of pre-playback observation, four min of playback of one of the five possible playback treatments, and six min of post-playback observation. We scored the subjects' responses with a personal digital assistant (Palm $\left.{ }^{\mathrm{TM}} \mathrm{m} 105\right)$ with custom event recording software (courtesy of J. M. Burt at University of Washington, Seattle). Data collected in real time included the times when the bird sang or crossed one of the distance markers (specifying whether he was going toward or away from the speaker). From these data we computed the following seven response variables: (1) number of songs, (2) time spent within $15 \mathrm{~m}$ from the speaker, (3) closest distance bin of approach $(1=0-15 \mathrm{~m}, 2=15-25 \mathrm{~m}, 3=$ $25-50 \mathrm{~m}$, and $4=>50 \mathrm{~m})$, (4) distance bin after first approach $(1=0-15 \mathrm{~m} \ldots 4=>50 \mathrm{~m})$, (5) whether the subject approached or not within $15 \mathrm{~m}$ from the speaker $(0=$ no, $1=$ yes $)$, (6) latency to sing, and (7) latency to approach within $50 \mathrm{~m}$ of the speaker. We computed all response variables based on the combined playback and post-playback observations because responses were never restricted to the duration of the playback. 


\section{Statistical analyses}

It is generally desirable to assess the effect of playback treatments on a few composite variables extracted from the original response variables through multivariate techniques (McGregor 1992). Latency variables, however, are not suitable for data reduction procedures of this kind because in some trials birds do not perform the behavior in question during the period of time sampled (thus no values can be entered in the factor analysis for those observations). Treating such cases (known as right-censored observations) as missing data or replacing them with arbitrary values in the factor analysis is incorrect as these procedures alter the real distribution of the data and can lead to biased conclusions. Instead, to test for the effects of song complexity and switching rate on the latency to approach or sing we used regression models of survival analysis (Tabachnick and Fidell 2001) which can handle censored observations while addressing similar questions to a multiple regression. We used Minitab's (release 14.1; Minitab, State College, Pennsylvania) modified Newton-Raphson algorithm to calculate maximum likelihood estimates of our model parameters and we modeled our data on the Weibull distribution (goodness-of-fit of this distribution was assessed via Anderson-Darling statistic and Pearson correlation coefficient). We provide the cumulative probability plot of approach by a particular time (see Fig. 4) for readers to visually assess the direction of differences across treatments in the survival analysis. Note that although this plot conveys the direction of the differences uncovered by our statistical models it does not reflect the relative magnitude of the effects of between-song switching rate or within-song complexity because it does not correct for the effects of covariates or interaction terms and it does not show the extent of the variation observed within each treatment.

The remaining response variables were collapsed into three composite factors using factor analysis with varimax rotation. Note that the assumptions regarding the distributions of variables included in a factor analysis are not in force when this technique is only used descriptively (Tabachnick and Fidell 2001). We assessed the effects of within and betweensong versatility and the interaction between them on these composite factors with general linear mixed models (GLMM) in SAS (SAS Institute, Cary, North Carolina) using the containment method for computing the denominator degrees of freedom for the tests of fixed effects. To meet the normality assumptions for GLMM, we used cubic values of factor two and logtransformed values of factor three (data transformations followed Osborne 2002). We corrected for multiple sampling of the different subjects by including the identity of the test subject as a random factor in the GLMM and a categorical variable in the survival analyses. Besides applying a different order of presentation of treatments to the different individuals, we statistically corrected for order effects in our survival and GLMM models by including trial order as an ordinal variable in our models. We also corrected for the subjects' behavior prior to the playback by including the following three variables: (1) number of songs during preplayback, (2) number of calls during pre-playback and (3) closest bin of approach in preplayback $(1=0-15 \mathrm{~m} ; 4=50+\mathrm{m})$. We removed covariates and the interaction term from our final models (in that order) when their p-values were above 0.40 .

\section{Results}

Conspecific playback treatments produced fast and evident spatial responses. Males ( $\mathrm{n}=13)$ typically interrupted their current activities, approached the speaker to varying degrees and visibly inspected the surroundings after we had played only a few songs. Although most responses were quick, subjects were able to sample the between-song switching rate of the treatments before their first response. Males heard at least four playback songs before initiating approach in 72 out of the 85 trials (and heard at least two in 82 trials).

In contrast to the spatial responses, vocal responses to conspecific playback were generally weak. Test subjects sang fewer than four songs during the four minutes of playback in 57 trials 
(67\%). Furthermore, in 51 trials $(60 \%)$ they sang fewer than ten songs in the ten minutes of playback plus post-playback observation (a very low song rate when compared to courtship standards). Subjects that sang during trials usually did so softly during playback and loudly later on.

\section{Multivariate-measure analysis}

The first three factors derived from our factor analysis explained $92.1 \%$ of the total variation in our data (Table 1). Factor one reflected mainly the subjects' physical proximity to the speaker, factor two the time spent close to the speaker, and factor three the number of songs sung.

The proximity response score, factor one (Fig. 3), was significantly higher in trials with high versus low between-song switching rate (GLMM: $\left.F_{1,66}=6.43, P=0.014\right)$ and marginally higher in trials with low versus high song complexity (GLMM: $F_{1,66}=3.92, P=0.052$; Trial order and number of calls before playback were removed from final model). Higher scores for this factor translate to closer approaches to the speaker (Table 1). Factor two, the temporal response score, was not significantly affected by song complexity or switching rate (GLMM: Song complexity: $F_{1,68}=0.47, P=0.497$; Switching rate: $F_{1,68}=0.22, P=0.638$; Number of calls before playback, closest approach before playback and the interaction term were removed from final model), and neither was factor three, the vocal response score (GLMM: Song complexity: $F_{1,67}=0.43, P=0.515$; Switching rate: $F_{1,67}=0.04, P=0.85$; Interaction term: $F_{1,67}=1.37, P=0.245$; Number of songs before playback, closest approach before playback were removed from final model).

\section{Response latencies}

Subjects approached the speaker sooner in trials with low versus high within-song versatility (Survival analysis: $n=85,16$ right-censored values; $Z=2.25, P=0.025$ ) and showed a tendency to do the same in trials with high versus low between-song switching rate $(Z=-1.71, P=$ 0.087; Trial order and the interaction term were removed from final model) (Fig. 4a). Given that the assessment of vocal versatility (especially of between-song switching rate) requires some time, we repeated this analysis using only the subset of trials in which birds had heard four or more songs before responding. The effects of song complexity and switching rate were both significant in this case (Survival analysis: $n=72,16$ right-censored values; Song complexity, $Z=2.13, P=0.033$; Switching rate, $Z=-3.32, P=0.001$; Trial order, closest approach before playback and the interaction term were removed from final model) and the direction of the differences was the same as in the analysis of all samples.

The latency to sing after the initiation of playback was not significantly affected by the song complexity (Survival Analysis: $n=85,26$ right-censored values; $Z=0.01, P=0.990$ ) or switching rate of the stimulus $(Z=0.18, P=0.858$; Number of calls before playback and interaction term were removed from final model). The analysis of the subset of trials in which the subject's first song occurred after four or more playback songs revealed similar results (Survival analysis: $n=78,26$ right-censored values; Song complexity: $Z=-0.87, P=0.383$; Switching rate: $Z=-0,01, P=0.989$; Number of calls before playback and the interaction term were removed from final model).

\section{Heterospecific controls}

The differential response to repetitive versus complex playback songs cannot be attributed to our method of generating repetitive songs. The artificial generation of troupial songs (following the same method as the one used to produce the repetitive conspecific songs) did not alter the typical non-responsiveness of mockingbirds to the songs of sympatric troupials. Males did not vary the time they spent within $25 \mathrm{~m}$ of the speaker (paired $t$-test: $n=10$ males, $t=0.63, P=$ 
0.547 ), or the number of songs they sang (paired $t$-test: $n=10$ males, $t=0.46, P=0.656$ ) after hearing our heterospecific playback sequences. In the two occasions in which subjects came within $25 \mathrm{~m}$ of the speaker, individuals showed no evident signs of aggressiveness but rather approached gradually (while foraging) and remained foraging on the ground for the remainder of the trial.

\section{Discussion}

The response of male Tropical Mockingbirds to conspecific intruders is affected by the vocal versatility of their rivals. Both vocal versatility parameters manipulated in this experiment, song complexity and switching rate, influenced how fast and how close males approached the speaker during trials. As predicted, more repetitive singing at the within-song level was associated with stronger responses. However, this was not true at the between-song level where higher switching rates elicited more aggression. Similar opposing trends in within-song and between-song versatility have been reported for male Northern Cardinals (Cardinalis cardinalis), which reduce short-term versatility (by repeating the notes in a song a few extra times) and increase song switching rate in aggressive situations (Ritchison 1988). It is possible that senders increase the conspicuousness of their signals during agonistic encounters because of the striking contrast of low within-song versatility with high between-song versatility. Nevertheless, the lack of a significant interaction in our statistical models and the similar differences between levels of one parameter at the different levels of the other (Figs. 3 and 4) suggest that within- and between-song versatility serve independent purposes and/or transmit different information.

Four hypotheses could explain the responses of male Tropical Mockingbirds to variation in the vocal versatility of intruding males. First, vocal versatility may signal aggressive intentions in territorial contexts as observed in other oscines (reviewed in Vehrencamp 2000). Under this scenario, extremely repetitive songs may signal aggressiveness (because they are very different from the songs typically used in non-agonistic contexts, Vehrencamp 2000) while high song switching rates may be used to reduce receiver habituation (Falls and D'Agingcourt 1982). Given the qualitative differences of the effects of variation of within- and between-song versatility in this experiment, another possibility is that switching rate indicates a singer's aggressiveness (switching rate had a stronger effect on proximity score than song complexity) while song complexity indicates his willingness to attack (song complexity had a stronger effect on approach latency than switching rate).

The hypothesis that variation in vocal versatility is used to mediate territorial conflicts generates several testable predictions. First, it predicts that birds singing with low within-song versatility and high switching rate will approach a boundary and engage in territorial expansion or boundary disputes more often that birds singing in a different way. Given that Tropical Mockingbirds occasionally live in social groups in which several males defend a common territory (Morton et al. 2004, E. Laurent unpubl. data), this hypothesis also predicts that males living in polyandrous groups should sing repetitive songs and variable song sequences in response to potential intruders (i.e., neighbors or strangers) but not to fellow group members. Finally, since male mockingbirds sing mostly during courtship (Logan 1983) and since most natural countersinging events in the Tropical Mockingbird occur when at least one of the rivals is courting a female (Botero, personal observation), this hypothesis predicts that territorial conflicts are most prevalent while courting. Such a temporal bias in the frequency of territorial conflicts could occur if the area defended by males varies throughout the breeding cycle (see Biedenweg 1983). Nevertheless, the fact that most of our focal males did not sing back in response to playback (which seems to be also the case in the Northern Mockingbird, see Logan and Fulk 1984) does not support the idea that they use variation in vocal versatility as a mechanism for mediating territorial disputes. 
An alternative explanation is that the song of male Tropical Mockingbirds serves primarily a mate attraction function (as seems to be the case in the Northern Mockingbird, Derrickson and Breitwisch 1992) and that intruders singing with low within-song versatility and high-between song versatility represent a strong threat to the paternity of resident males. This hypothesis predicts that certain singing styles are more likely to yield extra-pair copulations than others and that resident males are able to block cuckolding attempts by responding aggressively to nearby singers (see Westneat and Stewart 2003; Kokko and Morrell 2005). In this case, immediate repetition of syllable types could for example show off a singer's ability to produce each song type consistently (Lambrechts and Dhondt 1988) while high switching rates could show off the size of his repertoire or help him reduce receiver habituation (Falls and D'Agingcourt 1982).

A third hypothesis is that variation in vocal versatility is a conventional signal of aggressive intentions (as in the first hypothesis), but that it is emitted in the context of competition for females and not for territory. Although conventional signals like the ones described here are not likely to influence female choice directly, they have the potential to do so indirectly if females keep track of the outcome of competitive interactions between males (West et al. 1981; Berglund et al. 1996; Mennill et al. 2002; Collins 2004). Female mockingbirds are known to constantly re-assess their mates (Logan 1997), and divorce, mate switching, facultative monogamy and extra-pair copulations also occur in this group (Derrickson 1989; Logan 1991; Logan 1997; Morton et al. 2004). Intense countersinging interactions between neighboring male mockingbirds seem to be associated with female mate assessment (Logan 1997; Botero personal obs.). The hypothesis of competition over the access to reproductive females explains why countersinging occurs primarily when at least one of the males is courting and predicts that males singing with low within-song versatility and high between-song versatility will tend to interact aggressively with their rivals. In contrast to the first hypothesis, it predicts that males living in polyandrous groups will also use this singing style in response to adult males of the same territory if both of them are unrelated to the breeding female.

A fourth alternative is that the song of male Tropical Mockingbirds serves both mate-attraction and territorial functions and that variation at the two levels of vocal versatility is intended for receivers of different sexes. For example, it is possible that high switching rates are employed to attract females (e.g. Catchpole et al. 1984; Buchanan and Catchpole 1997; Langmore 1997; Collins 1999) and that repetitive songs are used to show aggression in male-male interactions (Vehrencamp 2000). Under this scenario, resident males would be most threatened by male-aggressive female-attractive singers, somewhat less threatened by male-nonaggressive female-attractive singers and much less threatened by male-non-aggressive femalenon-attractive singers.

At this point we can only conclude that male Tropical Mockingbirds pay attention to the vocal versatility of other males and that they perceive intruders singing repetitive songs or variable song sequences as a stronger threat than those that sing complex songs or repetitive song sequences. We are currently pursuing definitive tests of these alternatives.

\section{Acknowledgments}

We would like to thank S. Despa and F. Vermeylen (Cornell Statistical Consulting Office) for their advice on statistical procedures. Many thanks as well to R. Boy (at Kunuku Warahama), and G. van Hoorn and P. Montanus (at Dienst Ruimtelijke Ordening en Beheer Bonaire) for their logistic support while in the field, to N. Bloch for her assistance in the collection of data for this project and to A. Kock, N. Bouten and their families for their incredible hospitality. This manuscript greatly benefited from the comments and suggestions of three anonymous reviewers. Funding was provided by NIH grant R01MH60461. SYRINX software is available at www.syrinxpc.com. 


\section{LITERATURE CITED}

Berglund A, Bisazza A, Pilastro A. Armaments and ornaments: An evolutionary explanation of traits of dual utility. Biological Journal of the Linnean Society 1996;58:385-399.

Biedenweg DW. Time and energy budgets of the mockingbird (Mimus polyglottos) during the breeding season. Auk 1983;100:149-160.

Brewer, D.; MacKay, K. Wrens, dippers and thrashers. Yale University Press; New Haven, Connecticut: 2001.

Buchanan KL, Catchpole CK. Female choice in the sedge warbler, Acrocephalus schoenobaenus: Multiple cues from song and territory quality. Proceedings of the Royal Society of London, Series B 1997;264:521-526.

Burnett, LJ. MS thesis. University of North Carolina; Greensboro: 1978. Mockingbird song (Mimus polyglottos): An investigation within and across seasons.

Catchpole CK, Dittami J, Leisler B. Differential responses to male song repertoires in female songbirds implanted with estradiol. Nature 1984;312:563-564.

Catchpole, CK.; Slater, PJB. Bird song: biological themes and variations. Cambridge University Press; Cambridge, United Kingdom: 1995.

Collins SA. Is female preference for male repertoires due to sensory bias? Proceedings of the Royal Society of London, Series B 1999;266:2309-2314.

Collins, S. Vocal fighting and flirting: the functions of birdsong. In: Marler, P.; Slabbekoorn, H., editors. Nature's music, the science of birdsong. Elsevier Academic Press; San Diego, California: 2004. p. 39-79.

d'Agingcourt LG, Falls JB. Variation of repertoire use in the Eastern Meadowlark, Sturnella magna. Canadian Journal of Zoology 1983;61:1086-1093.

Derrickson KC. Yearly and situational changes in the estimate of repertoire size in Northern Mockingbirds (Mimus polyglottos). Auk 1987;104:198-207.

Derrickson KC. Variation in repertoire presentation in Northern Mockingbirds. Condor 1988;90:592606.

Derrickson KC. Bigamy in Northern Mockingbirds: circumventing female-female aggression. Condor 1989;91:728-732.

Derrickson, KC.; Breitwisch, R. Northern Mockingbird (Mimus polyglottos). In: Poole, A.; Stettenheim, P.; Gill, F., editors. The birds of North America, no 7. Philadelphia: The Academy of Natural Sciences; Washington, DC: The American Ornithologists' Union; 1992.

Dixon K. Patterns of singing in a population of the Plain Titmouse. Condor 1969;71:94-101.

Falls JB, d'Agingcourt. Why do meadowlarks switch song types. Canadian Journal of Zoology 1982;60:3400-3408.

Falls JB, Krebs JR. Sequence of songs in repertoires of Western Meadowlarks (Sturnella neglecta). Canadian Journal of Zoology 1975;53:1165-1178.

Holdridge, LR. Life zone ecology. Tropical Science Center; San Jose, Costa Rica: 1967.

Horn AG, Falls JB. Song switching in mate attraction and territory defense by Western Meadowlarks (Sturnella neglecta). Ethology 1991;87:262-268.

Howell, SNG.; Webb, S. A guide to the birds of Mexico and northern Central America. Oxford University Press; Oxford, United Kingdom: 1995.

Kokko H, Morrell LJ. Mate guarding, male attractiveness, and paternity under social monogamy. Behavioral Ecology 2005;16:724-731.

Kramer HG, Lemon RE, Morris MJ. Song switching and agonistic stimulation in the Song Sparrow (Melospiza melodia): Five tests. Animal Behaviour 1985;33:135-149.

Lambrechts M, Dhondt AA. The anti-exhaustion hypothesis - a new hypothesis to explain song performance and song switching in the Great Tit. Animal Behaviour 1988;36:327-334.

Langmore NE. Song switching in monandrous and polyandrous Dunnocks, Prunella modularis. Animal Behaviour 1997;53:757-766. 
Laurent, E. Tesis de Licenciatura. Caracas, Venezuela: Universidad Central de Venezuela; 1990. Estudio del sistema de reproducción comunal y de algunos aspectos de la historia natural de la Paraulata Llanera (Mimus gilvus) en los llanos centrales de Venezuela. Unpub.

Lein MR. Song variation of Chestnut-sided Warblers: its nature and suggested significance. Canadian Journal of Zoology 1978;56:1226-1283.

Lemon RE. The relation between organization and song in cardinals, Richmondena cadinalis. Behaviour 1968;32:158-177.

Logan CA. Reproductively dependent song cyclicity in mated male mockingbirds (Mimus polyglottos). Auk 1983;100:404-413.

Logan CA. Mate switching and mate choice in female Northern Mockingbirds: facultative monogamy. Wilson Bulletin 1991;103:277-281.

Logan CA. Mate re-assessment in an already-mated female Northern Mockingbird. Chat 1997;67:108112.

Logan CA, Fulk KR. Differential responding to spring and fall song in mockingbirds (Mimus polyglottos). Journal of Comparative Psychology 1984;98:3-9.

McGregor, PK. Quantifying responses to playback: one, many, or composite multivariate measures?. In: McGregor, PK., editor. Playback and studies of animal communication. Plenum Press; New York: 1992. p. 79-96.

Mennill DJ, Ratcliffe LM, Boag PT. Female eavesdropping on male song contests in songbirds. Science 2002;296:873-873. [PubMed: 11988564]

Molles LE, Vehrencamp SL. Repertoire size, repertoire overlap, and singing modes in the Banded Wren (Thryothorus pleurostictus). Auk 1999;116:677-689.

Morton ES, Stutchbury BJM, Piper WH. Cooperative breeding in the Tropical Mockingbird (Mimus gilvus) in the Panama Canal Zone. Ornitología Neotropical 2004;15:417-421.

Nielsen BMB, Vehrencamp SL. Responses of Songs Sparrows to song-type matching via interactive playback. Behavioral Ecology and Sociobiology 1995;37:109-117.

Osborne, J. Practical Assessment, Research and Evaluation 8. 2002. Notes on the use of data transformations. [Online] Available at pareonline.net/

Read AF, Weary DM. The evolution of bird song - comparative analyses. Philosophical Transactions of the Royal Society of London, Series B 1992;338:165-187.

Ritchison G. Song repertoires and the singing behavior of male Northern Cardinals. Wilson Bulletin 1988;100:583-603.

Searcy WA, Nowicki S, Hogan C. Song type variants and aggressive context. Behavioral Ecology and Sociobiology 2000;48:358-363.

Searcy WA, Podos J, Peters S, Nowicki S. Discrimination of song types and variants in Song Sparrows. Animal Behaviour 1995;49:1219-1226.

Searcy WA, Yasukawa K. Use of the song repertoire in intersexual and intrasexual contexts by male Redwinged Blackbirds. Behavioral Ecology and Sociobiology 1990;27:123-128.

Tabachnick, BG.; Fidell, LS. Using multivariate statistics. Allyn and Bacon, Needham Heights; Massachusetts: 2001.

Vehrencamp, SL. Handicap, index and conventional signal elements of bird song. In: Espmark, YO; Amundsen, T.; Rosenqvist, G., editors. Animal signals: signaling and signal design in animal communication. Tapir Academic Press; Trondheim, Norway: 2000. p. 277-300.

West MJ, King AP, Eastzer DH. Validating the female bioassay of cowbird song - relating differences in song potency to mating success. Animal Behaviour 1981;29:490-501.

Westneat DF I, Stewart RK. Extra-pair paternity in birds: Causes, correlates, and conflict. Annual Review of Ecology Evolution and Systematics 2003;34:365-396.

Wildenthal JL. Structure in primary song of the mockingbird (Mimus polyglottos). Auk 1965;82:161189.

Wiley RH, Godard R, Thompson ADJ. Use of two singing modes by Hooded Warblers as adaptations for signaling. Behaviour 1994;129:243-278. 

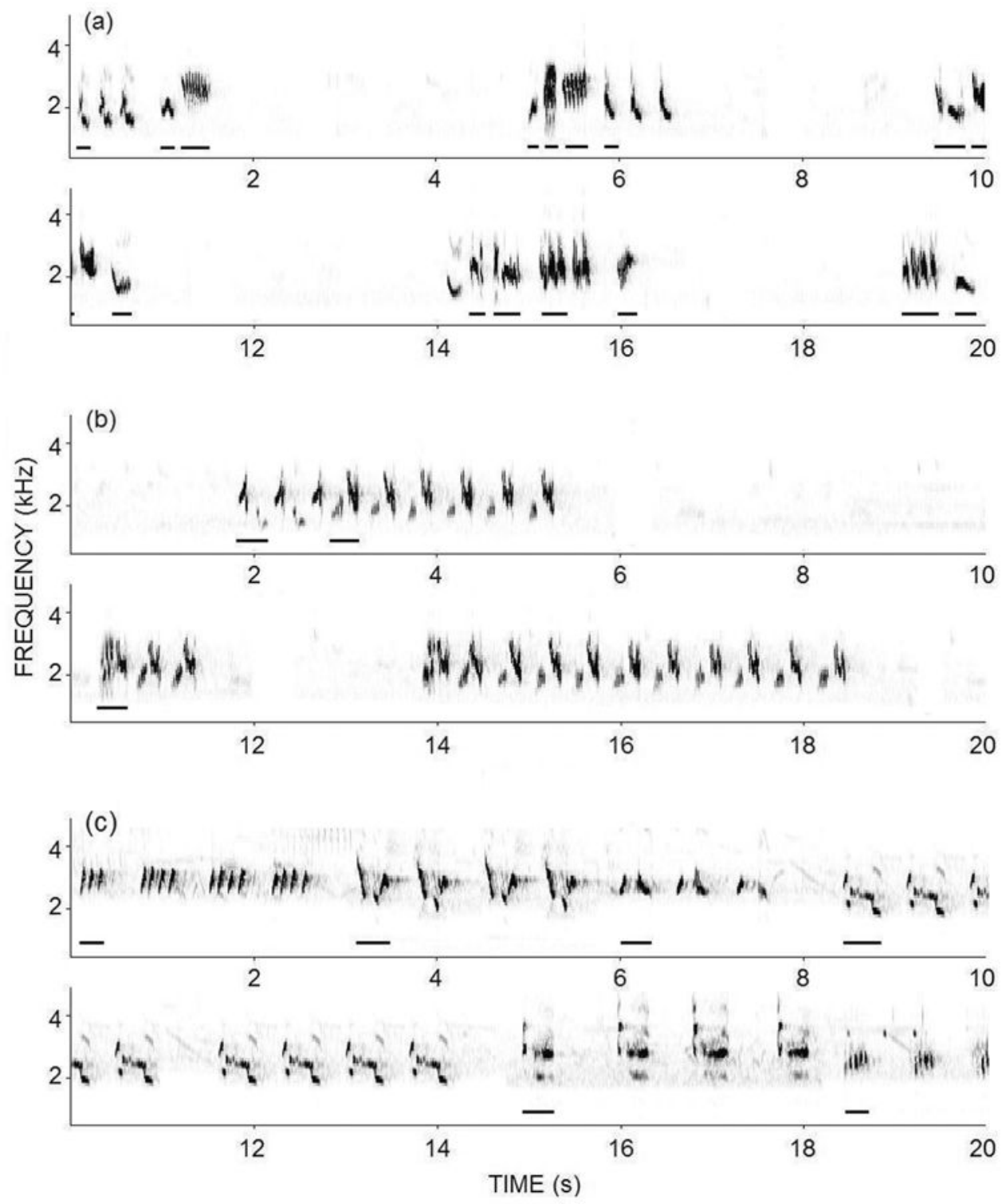

Fig. 1.

Variation in the song versatility of the Tropical Mockingbird. The typical song sequences in our population have high within-song versatility (song complexity) and high between-song versatility (switching rate) (a). Occasionally, males become more repetitive at the within-song and between-song level (b). Both sequences were recorded from the same male Tropical Mockingbird within a period of $30 \mathrm{~min}$. New syllable types have been underlined as they are introduced for the first time. A typical courtship solo of a Northern Mockingbird (c) is also shown for comparison. 


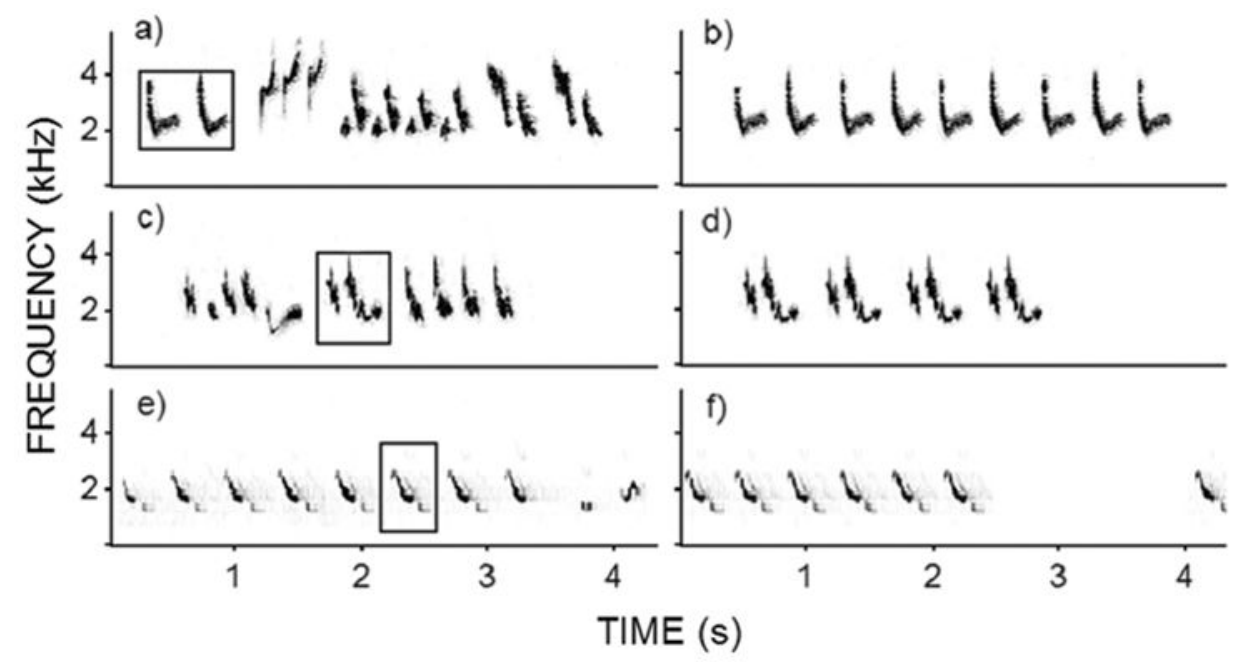

Fig. 2 .

Examples of complex songs obtained from recordings of male Tropical Mockingbirds in Bonaire (a, c) and the repetitive songs we derived from them (b, d). Note the similarity between the derived songs and the natural examples of repetitive songs shown in Figure 1b. The bottom panels show a song from a sympatric Icterus icterus (e) and the heterospecific control song derived from it (f). 


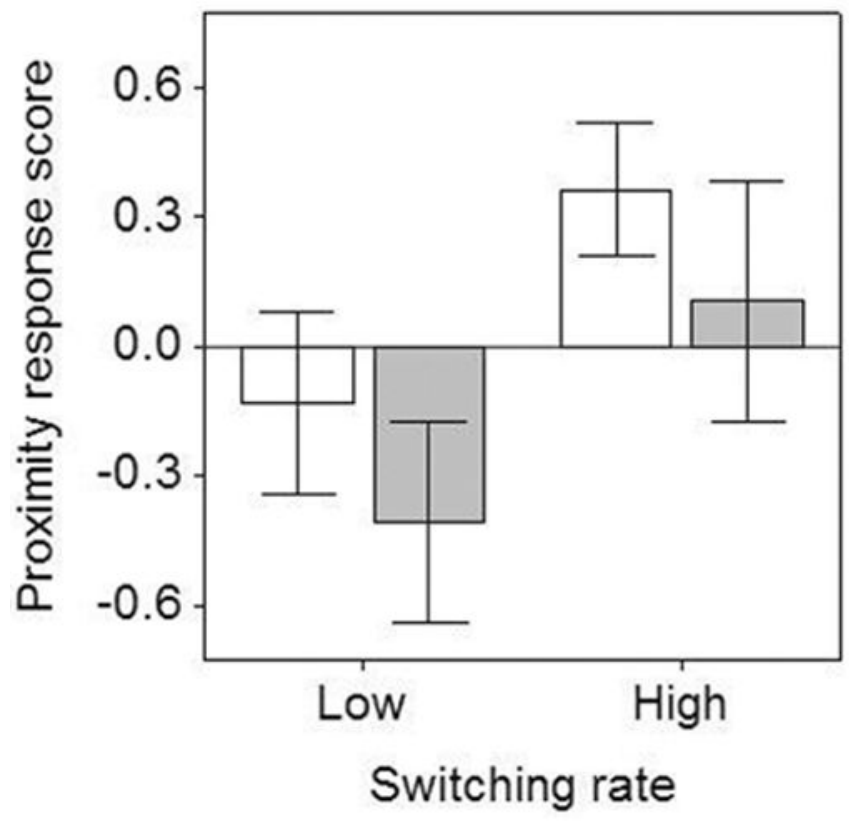

Fig. 3.

Mean proximity response scores during playback trials with low (white bars) and high (gray bars) within-song versatility at low and high between-song switching rates. Error bars reflect one SE. Higher score values correspond to closer approach. 


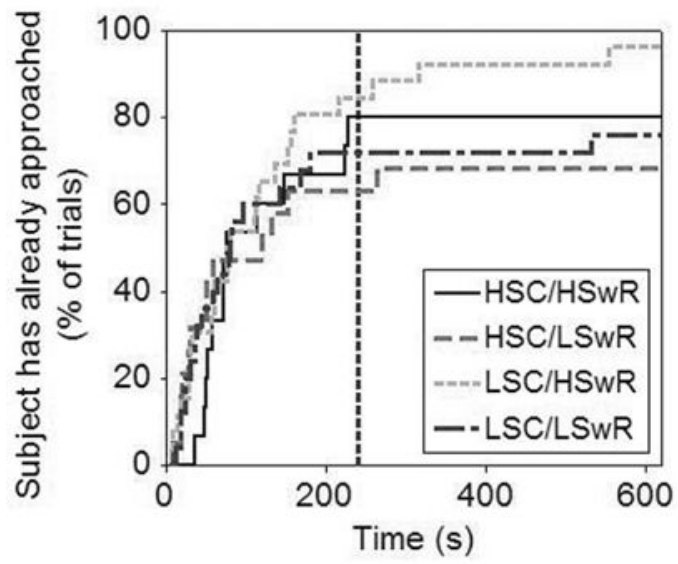

Fig. 4.

Kaplan-Meier cumulative plot of the latency to approach during trials. A vertical dotted line marks the end of the playback period. Convention: HSC = High Song Complexity; LSwR = Low Switching Rate. 
Table 1

Principal Components Factor Analysis after varimax rotation.

\begin{tabular}{ccccc}
\hline Variable $^{\boldsymbol{a}}$ & Factor $^{\boldsymbol{b}}$ & Factor $^{\boldsymbol{b}}$ & Factor $^{\boldsymbol{b}}$ & Communality $^{\boldsymbol{b}}$ \\
\hline SONGS & $0.123(-0.136)$ & $-0.067(0.033)$ & $0.983(0.995)$ & 0.985 \\
TS<15 & $0.388(-0.383)$ & $-0.918(-1.251)$ & $0.080(-0.041)$ & 1.000 \\
CLOSEST & $-0.908(-0.463)$ & $0.259(-0.234)$ & $-0.212(-0.039)$ & 0.937 \\
FIRST & $-0.844(-0.470)$ & $0.247(-0.193)$ & $0.040(0.211)$ & 0.775 \\
APP $<15$ & $0.874(0.399)$ & $-0.312(0.121)$ & $0.212(-0.042)$ & 0.905 \\
$\%$ Variance & 0.493 & 0.215 & 0.213 & 0.921 \\
\hline
\end{tabular}

${ }^{a}$ Added responses during and after playback: SONGS = Number of songs; TS $<15=$ Time spent within $15 \mathrm{~m}$ from speaker; CLOSEST $=$ Closest distance bin of approach; FIRST = Distance bin after first approach; APP $<15=$ Subject came within $15 \mathrm{~m}$ of the speaker (see text for details).

$b_{\text {Loading (score coefficient). }}$ 